\title{
A recommendation of computation of normal streeses in single point incremental forming technology
}

- Le Khanh Dien

- Nguyen Thanh Nam

- Nguyen Thien Binh

DCSELAB, University of Technology, VNU-HCM

(Manuscript Received on December 11 $1^{\text {th }}, 2013$; Manuscript Revised March 18 ${ }^{\text {th }}, 2014$ )

\section{ABSTRACT:}

Single Point Incremental Forming (SPIF) has become popular for metal sheet forming technology in industry in many advanced countries. In the recent decade, there were lots of related studies that have concentrated on this new technology by Finite Element Method as well as by empirical practice. There have had very rare studies by pure analytical theory and almost all these researches were based on the formula of ISEKI. However, we consider that this formula does not reflect yet the mechanics of destruction of the sheet work piece as well as the behavior of the sheet in reality.

The main aim of this paper is to examine ISEKI's formula and to suggest a new analytical computation of three elements of stresses at any random point on the sheet work piece. The suggested formula is carefully verified by the results of Finite Element Method simulation.

Keywords: SPIF, Strains, Stresses, Computation, FEM Analysis.

1. AN OVERVIEW OF ISEKI'S FORMULA

SPIF (Single Point Incremental Forming) and TPIF (Two Point Incremental Forming) are two methods of ISF technology (Incremental Sheet Forming), a new metal foil forming technology without mould that was recommended by Leszak [1] in 1967. From 1997 to now on, this method has been developed and has definitively great results in industry such as the head of bullet train that was manufactured by Amino Corp. in Japan [6]. Researchers have attempted to form a general analytic formula of strength in material. Especially, Iseki recommended a popular formula that almost all researchers have used as a basic theoretical analysis for their empirical researches. According to [3], [4] the basic normal stresses of Iseki's formula are displayed in (1):

$$
\sigma_{\phi}=\sigma_{1}=\frac{\sigma_{Y} \cdot r_{\text {tool }}}{t+r_{\text {tool }}}>0
$$




$$
\begin{gathered}
\sigma_{t}=\sigma_{3}=-\frac{\sigma_{Y} . t}{t+r_{\text {tool }}}<0 \\
\sigma_{\theta}=\sigma_{2}=\frac{1}{2}\left(\sigma_{1}+\sigma_{3}\right)=\frac{\sigma_{Y}}{2}\left(\frac{-t+r_{\text {tool }}}{t+r_{\text {tool }}}\right)
\end{gathered}
$$

Herein:

$\sigma y$ is the Yield stress of sheet workpiece, it is constant and depends on the characteristic of sheet material,

rtool is radius of spherical tip of no cutting edges tool.

$\mathrm{t}$ is the thickness of the sheet workpiece.

In examination of Iseki's formula in (1) we could find out some important problems:

The stresses at a random point in the sheet workpiece are always constant so they are independent to the position of the tool on the sheet workpiece that could not explain the reason of the worksheet. In the other hand, these stresses are equal the 3 principal stresses.

When calculating the partial differential of thickness $t$ of 3 elements stresses of Iseki's formula in (1) we have result:

$$
\begin{aligned}
& \frac{\partial \sigma_{\phi}}{\partial t}=\frac{-\sigma_{Y} \cdot r_{\text {tool }}}{\left(t+r_{\text {tool }}\right)^{2}}<0 \\
& \frac{\partial \sigma_{t}}{\partial t}=-\frac{\sigma_{Y} \cdot r_{\text {tool }}}{\left(t+r_{\text {tool }}\right)^{2}}<0 \\
& \frac{\partial \sigma_{\theta}}{\partial t}=-\frac{\sigma_{Y} r_{\text {tool }}}{\left(t+r_{\text {tool }}\right)^{2}}<0
\end{aligned}
$$

That means that all 3 elements of stresses are inverse to the thickness $t$ of the sheet workpiece. So when the thickness of workpiece increases, all stresses as well as forming force and consuming power will decrease. This is the paradoxical result of the Iseki's formula to the empirical reality.

By the above reason, this paper attempts to recommend a new more accuracy calculating of stresses by pure analytics formula that is base on Ludwik 's formula [5] and then check the results to the one of a FEM software such as Abaqus and comparison with the empirical result.

\section{A RECOMMENDED ANALYTICS FORMULA OF THE GENERATED STRESSES IN SPIF}

Model of calculating stresses at a random point in contact area of tool and sheet workpiece are described in figure 1 with the initial assumption:

Spherical tip of forming tool is absolute rigid and it keeps its geometric shape under interactive forces. A tiny layer of lubrication exist between tool tip and sheet workpiece surface for keeping a small constant coefficient of friction $\mathrm{f}$

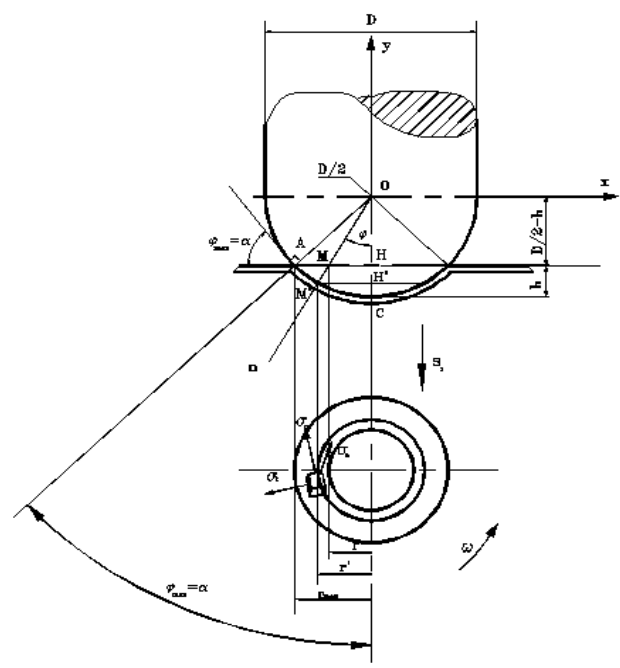

Figure 1. Model of calculating normal stresses in SPIF 
In figure 2, considering an initial random point $\mathrm{M}$ in the medium layer of the sheet. When the sheet is deformed, $\mathrm{M}$ will displaces to $\mathrm{M}^{\prime}$ that is also on this medium layer of the sheet. This layer is now deformed to a spherical surface that is parallel to the one of the tool.

The coordinate system OXYZ is places at the center $\mathrm{O}$ of the tool. On figure 2, M and $\mathrm{M}^{\prime}$ are on the same line OM' that makes with the $\mathrm{OZ}$ axis an angle $\mathrm{COM}=\varphi$. Remember that $\mathrm{OY}$ axis is perpendicular to the surface of the figure. ti is initial thickness of the sheet and $t \varphi$ is the one at M'. The displacements of $M$ to 3 axis are show in low part of figure 2:

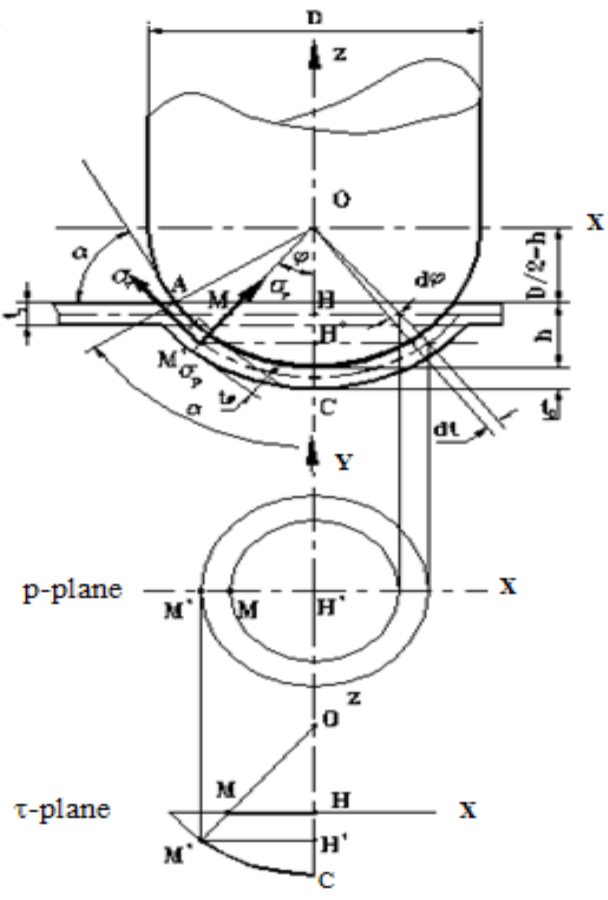

Figure 2. Absolute deformation of sheet workpiece in 3 perpendicular directions

p-plane: the plane that is perpendicular to $\mathrm{OZ}$ axis and parallel to OXY plane and passes through point $M^{\prime}$. It describes the circumference orbit of the cutting tool,

$\tau$-plane: the $\mathrm{OXZ}$ plane that pass through $\mathrm{M}$ and $M^{\prime}$. It is also the tangent direction of the profile of the tool. On $\tau$-plane, initial point $M$ displaced to M'and chord $\mathrm{MH}$ deformed to curve M'C,

$\mathrm{r}$ : radial direction or normal direction $\mathrm{n}$. In this direction, initial thickness ti follows Cos-law that means that $t \varphi=t i \cos \varphi$. When we call $t=t i$ is the initial thickness of the sheet hence $t \varphi=t \cos \varphi$,

$\mathrm{D}$ is diameter of tool $\mathrm{D}=2$. rtool.

\section{Computation strains and stresses at a} random point $M$ of the workpiece in contact area:

\section{- On p-direction:}

On figure $2, \mathrm{M}$ is located by angle $\mathrm{COM}=\varphi$ on the circumference of circle $(\mathrm{H}, \mathrm{r}=\mathrm{HM})$. Under the application force of the tool, this circle is extended to (H', r'=H'M'). Consider to 2 right triangle $\mathrm{MHO}$ and $\mathrm{M}^{\prime} \mathrm{H}^{\prime} \mathrm{O}$, initial radius is:

$M H=r=O H \cdot \operatorname{tg} \varphi=\left(\frac{D}{2}+\frac{t}{2}-h\right) \cdot \operatorname{tg} \varphi=\frac{t+D-2 h}{2} \operatorname{tg} \varphi$

The circumference of $(\mathrm{H}, \mathrm{r}=\mathrm{MH})$ is also the initial length to $\mathrm{p}$-direction:

$$
l_{0}=2 \pi \cdot r=2 \pi\left(\frac{t+D-2 h}{2}\right) \cdot \operatorname{tg} \varphi
$$

After deformed, initial circle $(\mathrm{H}, \mathrm{r}=\mathrm{MH})$ becomes (H', r'=M'H'):

$M^{\prime} H^{\prime}=r^{\prime}=O M^{\prime} \sin \varphi=\frac{D+t_{\varphi}}{2} \sin \varphi=\frac{D+t \cos \varphi}{2} \sin \varphi$ 
The circumference of $\left(H^{\prime}, r^{\prime}=M^{\prime} H^{\prime}\right)$ is also the deformed length to p-direction:

$$
l^{\prime}=2 \pi \cdot r^{\prime}=2 \pi \frac{D+t \cos \varphi}{2} \cdot \sin \varphi
$$

Strain of p-direction is calculated as:

$$
\varepsilon_{p}=\ln \frac{l^{\prime}}{l_{0}}=\ln \frac{2 \pi \frac{D+t \cos \varphi}{2} \cdot \sin \varphi}{2 \pi\left(\frac{t+D-2 h}{2}\right) \cdot \operatorname{tg} \varphi}=\ln \left(\frac{(D+t \cdot \cos \varphi) \cos \varphi}{D+t-2 h}\right)=\ln \left(\frac{t \cdot \cos ^{2} \varphi+D \cdot \cos \varphi}{t+D-2 h}\right)
$$

Notice that $\mathrm{r}^{\prime}=\mathrm{M}^{\prime} \mathrm{H}^{\prime}>\quad \mathrm{r}=\mathrm{MH}$ so $\mathrm{l}^{\prime}=2 \pi \mathrm{r}^{\prime}>$

$$
\sigma_{P}=K \varepsilon_{P}^{n}
$$

$10=2 \pi \mathrm{r}$ and $l^{\prime} / 10>1$, so

$$
\varepsilon_{p}=\ln \left(\frac{D+t-2 h}{D \cdot \cos \varphi+t \cdot \cos ^{2} \varphi}\right)>0
$$

$\mathrm{K}$ : Yielding coefficient

According to Ludwik's formula

$\mathrm{n}$ : Exponent value of plastic curve, the result is

$$
\sigma_{P}=K \ln ^{n}\left(\frac{D+t-2 h}{D \cdot \cos \varphi+t \cdot \cos ^{2} \varphi}\right)
$$

Calculating the differential of (3):

$$
\frac{\partial \sigma_{P}}{\partial t}=n \cdot K \frac{\cos \varphi(D(1-\cos \varphi)+2 h \cos \varphi)}{(t+D-2 h)\left(t \cdot \cos ^{2} \varphi+D \cdot \cos \varphi\right)} \ln ^{n-1}\left(\frac{t+D-2 h}{t \cdot \cos ^{2} \varphi+D \cdot \cos \varphi}\right)>0
$$

Because: $\quad \mathrm{D}>2 \mathrm{~h}, \quad \cos \varphi>0, \quad \mathrm{t}>0$ and $\quad$ Strain to $\tau$-direction:

$$
\begin{gathered}
\varepsilon_{p}=\ln \left(\frac{D+t-2 h}{D \cdot \cos \varphi+t \cdot \cos ^{2} \varphi}\right)>0 \\
\text { So } \frac{\partial \sigma_{P}}{\partial t}>0
\end{gathered}
$$

$\sigma \mathrm{P}$ is proportional to the thickness t.

$$
\text { - On } \tau \text {-direction: }
$$

The deformation increases from tip of tool to margin of the contact circle and $\mathrm{M}$ displaces to M'. Initial length:

$$
l_{0}=M H=r=O H \cdot \operatorname{tg} \varphi=\left(\frac{D}{2}+\frac{t}{2}-h\right) \cdot \operatorname{tg} \varphi=\frac{D+t-2 h}{2} \operatorname{tg} \varphi
$$$$
\varepsilon_{t}=\ln \frac{l^{\prime}}{l_{0}}=\ln \frac{\frac{D+t \cdot \cos \varphi}{2} \varphi}{\frac{D+t-2 h}{2} \operatorname{tg} \varphi}=\ln \left(\frac{(t \cdot \cos \varphi+D) \varphi}{(t+D-2 h) \operatorname{tg} \varphi}\right)
$$

$$
\text { Because } l^{\prime}>10 \text { so } \varepsilon t>0
$$

Ludwik's formula is applied for $\tau$-direction:

$$
\begin{aligned}
& \sigma_{t}=K \varepsilon_{t}^{n} \\
& \sigma_{t}=K \ln ^{n}\left(\frac{(t \cos \varphi+D) \varphi}{(t+D-2 h) \operatorname{tg} \varphi}\right)
\end{aligned}
$$

Calculating the differential of $\sigma \mathrm{t}$ : $\frac{\partial \sigma_{t}}{\partial t}=K n\left(\frac{D(\cos \varphi-1)-2 h \cos \varphi}{(t+D-2 h) \operatorname{tg}^{2} \varphi(t \cos \varphi+D)} \ln ^{n-1}\left(\frac{(t \cos \varphi+D) \varphi}{(t+D-2 h) \operatorname{tg} \varphi}\right)<0\right.$ - On r-direction:

Remained deformation on radial r-direction or normal $n$-direction to the thickness of the sheet at 
point M'. Sheet is extended to p-direction and tdirection is pressed in r-direction. According to [4] the relation of the initial thickness of sheet ti at $M$ ' and the deformed thickness $t \varphi$ followed Cos law $l^{\prime}=t_{\varphi}=t_{i} \cos \varphi$

Strain to r-direction:

$$
\varepsilon=\ln \frac{l^{\prime}}{l_{0}}=\ln \frac{t_{i} \cos \varphi}{t_{i}}=\ln (\cos \varphi)
$$

Ludwik's formula applied for r-direction:

$$
\begin{aligned}
& \sigma_{r}=K \varepsilon_{r}^{n} \\
& \sigma_{r}=K \ln ^{n}(\cos \varphi) \\
& \frac{\partial \sigma_{r}}{\partial t}=0
\end{aligned}
$$

So stress of this direction is not depended on the thickness $\mathrm{t}$

In conclusion, referring to the result of (3), (4) and (5) we can see that in among 3 normal stresses at a random point:

- $\sigma \mathrm{p}$ is proportional to the thickness $\mathrm{t}$ of the sheet workpiece,

- $\sigma \mathrm{t}$ is inverse to the thickness $\mathrm{t}$ of the sheet workpiece,
- or is independent to the thickness $t$ of the sheet workpiece,

$$
\begin{aligned}
& \sigma_{P}=K \ln ^{n}\left(\frac{D+t-2 h}{D \cdot \cos \varphi+t \cdot \cos ^{2} \varphi}\right) \\
& \sigma_{t}=K \ln ^{n}\left(\frac{(t \cos \varphi+D) \varphi}{(t+D-2 h) \operatorname{tg} \varphi}\right) \\
& \sigma_{r}=K \ln ^{n}(\cos \varphi)
\end{aligned}
$$

So the result of normal stresses is written in (6), these stresses have a complicated relation to the thickness $\mathrm{t}$ of the sheet, it could not be always inverse to the thickness of the sheet as in the result of Iseki's formula in (1).

This result will be checked with Abaqus simulation

\section{CHECKING FEM AND ABAQUS SIMULATION}

In FEM simulation, we apply forming process model of SPIF in Abaqus software for stainless steel 304L sheet with different thickness $0,1 \mathrm{~mm}$ and $0,4 \mathrm{~mm}$. The mechanical properties of empirical model sheets by documents and by testing are given in the following tabula and diagram:

Model 1: thickness is $1 \mathrm{~mm}$

\begin{tabular}{|c|c|c|c|c|}
\hline & Parameters & Symbol & Value & Notice \\
\hline 1 & Material of sheet workpiece & - & $\begin{array}{c}\text { Stainless steel } \\
304\end{array}$ & \\
\hline 2 & Young's modulus & $\mathrm{E}(\mathrm{Pa})$ & $203 . \mathrm{E}+9$ & \\
\hline 3 & Poisson's coefficient & $\mu$ & 0.33 & \\
\hline 4 & Plastic diagram & & (attached) & $\begin{array}{c}\text { Performed by Laboratory } \\
\text { of Faculty of Material } \\
\text { Engineering, HCMUT }\end{array}$ \\
\hline 5 & Thickness & $\mathrm{t}(\mathrm{mm})$ & 0,1 & \\
\hline 6 & Vertical Feed rate & $\Delta \mathrm{z}(\mathrm{mm})$ & 1 & \\
\hline
\end{tabular}


SCIENCE \& TECHNOLOGY DEVELOPMENT, VOI 17, No.K2- 2014

\begin{tabular}{|c|c|c|c|c|}
\hline 7 & Orbit Feed rate & $\mathrm{F}_{\mathrm{xy}}(\mathrm{mm} / \mathrm{min})$ & 1000 & \\
\hline 8 & Revolution per minute of spindle & $\mathrm{n}(\mathrm{RPM})$ & 500 & \\
\hline 9 & Diameter of tool & $\mathrm{D}(\mathrm{mm})$ & 5 & \\
\hline 10 & Mesh dimension & $\mathrm{a}(\mathrm{mm})$ & 1 & \\
\hline
\end{tabular}

Model 2: thickness is $0,4 \mathrm{~mm}$

\begin{tabular}{|c|l|c|c|c|}
\hline & \multicolumn{1}{|c|}{ Parameters } & Symbol & Value & Notice \\
\hline 1 & Material of sheet workpiece & - & Stainless steel 304 & \\
\hline 2 & Young's modulus & $\mathrm{E}(\mathrm{Pa})$ & $203 . \mathrm{E}+9$ & \\
\hline 3 & Poisson's coefficient & $\mu$ & 0.33 & \\
\hline 4 & Plastic diagram & & (attached) & $\begin{array}{l}\text { Performed by Laboratory of } \\
\text { Faculty Materials } \\
\text { Engineering, HCMUT }\end{array}$ \\
\hline 5 & Thickness & $\mathrm{t}(\mathrm{mm})$ & 0,4 & \\
\hline 6 & Vertical Feed rate & $\Delta \mathrm{z}(\mathrm{mm})$ & 1 & \\
\hline 7 & Orbit Feed rate & $\mathrm{F}_{\mathrm{xy}}(\mathrm{mm} / \mathrm{min})$ & 1000 & \\
\hline 8 & Revolution per minute of spindle & $\mathrm{n}(\mathrm{RPM})$ & 500 & \\
\hline 9 & Diameter of tool & $\mathrm{D}(\mathrm{mm})$ & 5 & \\
\hline 10 & Mesh dimension & $\mathrm{a}(\mathrm{mm})$ & 1 & \\
\hline
\end{tabular}

\subsection{Result of simulation of $0,1 \mathrm{~mm}$ thickness} model

Shapes of 2 models of in Abaqus are circular conic lateral and tool material is HSS with haft spherical tip of $5 \mathrm{~mm}$ diameter.

The processes of simulation and the result of simulation of $0,1 \mathrm{~mm}$ thickness model are displayed in figure 3 and figure 4 :

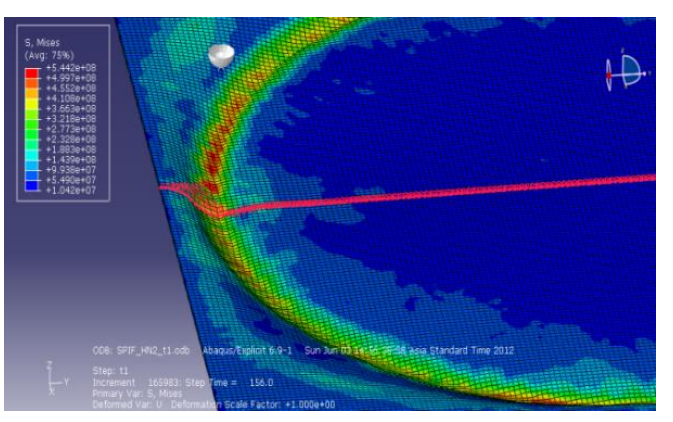

Figure 3. Stresses of simulated sheet $0,1 \mathrm{~mm}$ thickness and red diameter band on the model is the position of measure stresses

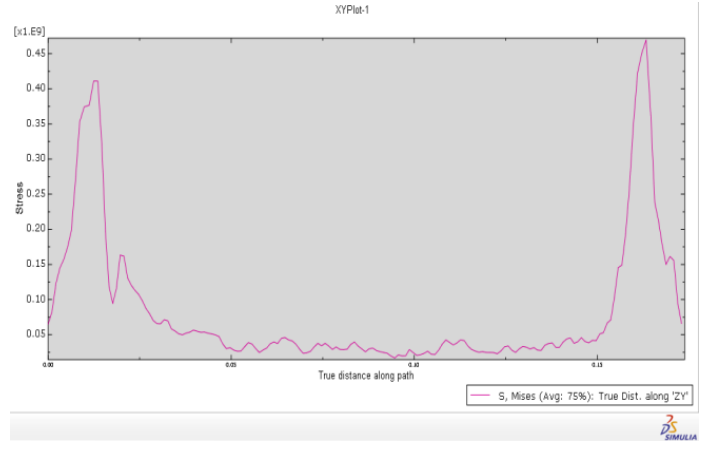

Figure 4. Diagram of stresses of $0,1 \mathrm{~mm}$ thickness through the diameter band

\subsection{Result of simulation of $\mathbf{0 , 4 m m}$ thickness model:}

The processes of simulation and the result of simulation of $0,4 \mathrm{~mm}$ thickness model are displayed in figure 7 and figure 8 : 


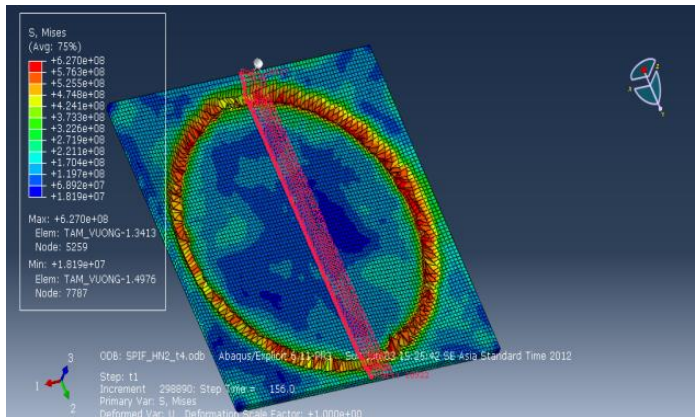

Figure 5. Stresses diagram of simulated sheet of $0,4 \mathrm{~mm}$ thickness, the red diameter band on the model is the position of measure stresses.

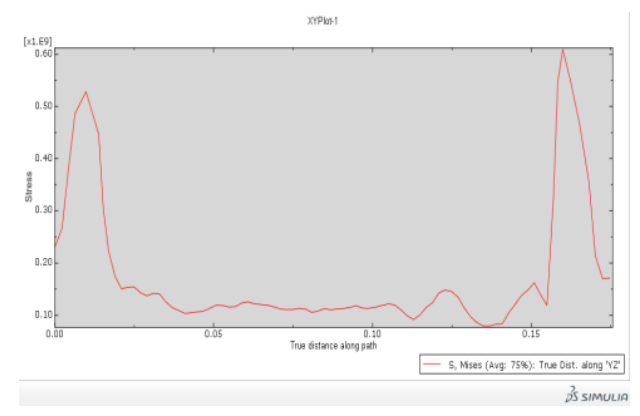

Figure 6. Diagram of stresses of $0,4 \mathrm{~mm}$ thickness through the diameter band of the material

The comparison of 2 diagrams of tresses of simulation in Abaqus is displayed in figure 9:

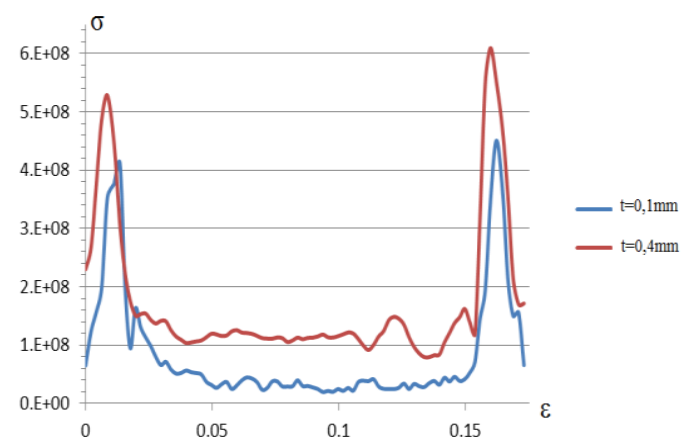

Figure 7. The comparison of stresses of 2 models with different thickness
So the normal stresses in simulation of the $0,4 \mathrm{~mm}$ thickness model are almost all bigger than the one of $0,1 \mathrm{~mm}$ thickness but there are some position the result is inversed. That means the normal stresses are proportional and sometimes inverse to the thickness of the workpiece as the result of recommended formula (3), (4) and (5).

\section{CONCLUSIONS}

In conclusion, the simulation in Abaqus proves that recommended formula in (6) is approval and more convincing then the Iseki's formula in (1). Figure 9 shows that the Iseki's formula is not true and could not explicable for the result of the simulation by Abaqus software.

ACKNOWLEDGMENTS: This research was supported by National Key Laboratory of Digital Control and System Engineering (DCSELAB), HCMUT, VNU-HCM. 


\section{Đề xuất một phương pháp tính ứng suất pháp trong công nghệ SPIF}

- Lê Khánh Điền

- Nguyễn Thanh Nam

- Nguyễn Thiên Bình

DCSELAB, Trường Đại học Bách Khoa, ĐHQG - HCM

\section{TÓM TÁT:}

Ngày nay, tạo hình tấm bằng công nghệ biến dạng cục bộ liên tục (Single Point Incremental Forming - SPIF) đã trở nên quen thuộc trong kỹ nghệ tại các nước tiên tiến. Trong vòng 10 năm gần đây, có nhiều nghiên cứu tập trung vào công nghệ mới này bằng phương pháp Phần tử hữu hạn (PPPTHH) cũng như bằng phương pháp thực nghiệm nhưng có rất ít công trình nghiên cứu thuần giải tích về vấn đề này và phần lớn đều dựa trên công thức của ISEKI. Tuy nhiên, chúng tôi nhận thấy rằng công thức này chưa thể hiện đúng được cơ chế ứng xử và phá hủy của vật liệu so với thực tế.

Do đó mục đích chính của bài viết này là phân tích lại công thức ISEKI từ đó đề nghị một công thức tính ứng suất pháp bằng giải tích mới được cho rằng phù hợp hơn. Công thức đề nghị này cũng được kiểm chứng bằng kết quả mô phỏng của phần mềm PPPTHH.

Từ khóa: SPIF, Biến dạng, Ứng suất, Tính toán, Phân tích PPPTHH

\section{REFERENCES}

[1]. Leszak, E., Patent: Apparatus and process for incremental dieless forming. United States Patent Office, Patent number 3,342,051 (1967).

[2]. Martin Skjoedt, Rapid Prototyping by Single Point IncrementalForming of Sheet Metal, PhD Project, Department of Mechanical Engineering,Technical University of Denmark, (2008).

[3]. Iseki $\mathrm{H}$, Kumon $\mathrm{H}$, Forming limit of incremental sheet metal stretch forming using spherical rollers, Journal of the Japan
Society for Technology of Plasticity, 35(406):1336-41 (1994).

[4]. Iseki $\mathrm{H}, \mathrm{An}$ approximate deformation analysis and FEM analysis for the incremental bulging of sheet metal using a spherical roller, Journal of Materials Processing Technology, pg 150-154 (2001).

[5]. Jacob Lubliner, "Plasticity Theory", University of California at Berkeley, 2005

[6]. http://www.amino.co.jp/en/company/271.ht $\mathrm{ml}$ 